\title{
Enhancement of Cell Growth and Lipid Content of a Freshwater Microalga Scenedesmus sp. by Optimizing Nitrogen, Phosphorus and Vitamin Concentrations for Biodiesel Production
}

\author{
Neumara L. S. Hakalin¹, Amanda P. Paz ${ }^{2}$, Donato A. G. Aranda², Lídia Maria P. Moraes \\ ${ }^{1}$ Department of Cell Biology, University of Brasília, Brasília, Brazil \\ ${ }^{2}$ Department of Chemical Engineering, Federal University of Rio de Janeiro, Rio de Janeiro, Brazil \\ Email: neumarahakalin@globo.com.br
}

Received 4 July 2014; revised 5 August 2014; accepted 14 August 2014

Copyright (C) 2014 by authors and Scientific Research Publishing Inc.

This work is licensed under the Creative Commons Attribution International License (CC BY).

http://creativecommons.org/licenses/by/4.0/

(c) (i) Open Access

\begin{abstract}
The effects of nitrogen, phosphorus and vitamin on growth and lipid content of a freshwater microalgae Scenedesmus sp. were investigated under indoor conditions. Nitrogen, phosphorus and vitamin presented significant statistical effect on lipid content, and a maximum lipid content of $\mathbf{2 9 . 3 \%}$ was obtained, corresponded to increases of $90 \%$ when compared to those obtained with the original nutrients medium. On the other hand, only nitrogen and phosphorus presented significant statistical effect on cell growth, achieving ash free dry biomass, algal density, and specific growth rate of $1.3 \mathrm{~g} \cdot \mathrm{L}^{-1}, 1.5 \mathrm{E}+07$ cells $\mathrm{mL}^{-1}$, and $0.62 \mathrm{~d}^{-1}$, respectively. By the use of the desirability function, it was possible to maximize the cell growth and lipid content simultaneously. The fatty acid composition of the microalgal lipid comprises over $80 \%$ of saturated and monounsaturated fatty acids. Thus, Scenedesmus sp. biomass could be used as suitable feedstock for biodiesel production.
\end{abstract}

\section{Keywords}

Scenedesmus sp., Phototrophic Cultivation, Nutrient Optimization, Lipid Accumulation, Algal Biodiesel 


\section{Introduction}

The global environment is currently threatened by a sharp rise in $\mathrm{CO}_{2}$ emissions, which have a significant impact on climate change. In light of this, more attention is being paid to efforts to reduce such emissions, and various physical, chemical, and biological methods have been applied to capture $\mathrm{CO}_{2}$. Among these, the biological method using photosynthetic microalgae is considered as one of the most important, effective and environmental-friendly approaches to fixing $\mathrm{CO}_{2}$ [1]. Microalgae biomass contains approximately $50 \%$ of carbon on a dry weight basis, and all the carbon present in cell is usually from carbon dioxide. With the production of 100 tons of microalgae biomass, around 180 tons of $\mathrm{CO}_{2}$ can be disposed using natural or artificial light [2]. Moreover, the biomass produced by photosynthetic microalgae can be transformed into a wide range of valuable products, such as biofuels, foods additives, health-care products, and so on, giving additional benefits from microalgal $\mathrm{CO}_{2}$ reduction process [3]. Thus, algae have been suggested as a very good candidate for biofuel production [4].

Recently, liquid biofuels have received wide attention since they are made from non-toxic, biodegradable, and renewable resources, and their use can lead to a decrease in the emission of harmful air pollutants [3]. The most common liquid biofuels to date are biodiesel and bioethanol, which have been mostly produced from food crops (e.g. soybean, palm, sunflower, canola, and sugarcane). However, producing enough liquid biofuels from these feedstocks to satisfy the existing demand would have a serious impact on food supplies, rainforests, or arable land, and thus there is an urgent need to find new renewable sources [5], such as microalgae, whose lipid productivity/biomass is about 15 - 300 times that of conventional crops [6]. Among the microalgae, Scenedesmus and Chlorella species have the most desirable features for efficient and economic combination of $\mathrm{CO}_{2}$ fixation, wastewater treatment and lipid synthesis toward biodiesel production [7]-[9]. However, the economic feasibility for algae mass culture for biodiesel production greatly depends on a high biomass productivity and value lipid yield [10].

Several strategies have been applied to improve microalgae growth and lipid content. These include optimization of the medium compositions (e.g., type of carbon source, nitrogen, phosphorus, vitamins and salts) [11], physical parameters (e.g., pH, temperature and light intensity) [12], and type of metabolism (e.g., phototrophic, heterotrophic, mixotrophic and photoheterotrophic growth). Therefore, it is of importance to utilize appropriate cultivation conditions and medium composition (especially nitrogen source and its concentration) to achieve the best lipid production performance of microalgae species [13].

In this current study, the aim is to evaluate the effect of utilizing nitrogen and phosphorus as well as vitamin at various levels on Scenedesmus sp. phototrophic cultivation to identify the best conditions for the cell growth and lipid content simultaneously, and to evaluate the potential of using the microalgal biomass thus produced as biodiesel feedstock.

\section{Materials and Methods}

\subsection{Microalgal Strain and Nutrients Medium}

The Scenedesmus sp. SCIB-01 used in this study was isolated from Ibirité lagoon (2001'19"S 4403'32"O), Minas Gerais state, Brazil, and was maintained in ASM-1 medium [14] that consisted of $\left(\mathrm{mg} \cdot \mathrm{L}^{-1}\right)$ : $\mathrm{NaNO}_{3}, 170$; $\mathrm{MgSO}_{4} \cdot 7 \mathrm{H}_{2} \mathrm{O}, 49 ; \mathrm{MgCl}_{2} \cdot 6 \mathrm{H}_{2} \mathrm{O}, 41 ; \mathrm{CaCl}_{2} \cdot 2 \mathrm{H}_{2} \mathrm{O}, 29 ; \mathrm{KH}_{2} \mathrm{PO}_{4}, 17.4 ; \mathrm{Na}_{2} \mathrm{HPO}_{4} \cdot 12 \mathrm{H}_{2} \mathrm{O}, 35.6 ; \mathrm{FeCl}_{3}, 0.65 ;$ $\mathrm{H}_{3} \mathrm{BO}_{3}, 2.48 ; \mathrm{MnCl}_{2} \cdot 4 \mathrm{H}_{2} \mathrm{O}, 1.39 ; \mathrm{ZnCl}_{2}, 0.33 ; \mathrm{CoCl}_{2} \cdot 6 \mathrm{H}_{2} \mathrm{O}, 0.049 ; \mathrm{CuCl}, 0.0014 ; \mathrm{Na}_{2} \mathrm{EDTA} \cdot 2 \mathrm{H}_{2} \mathrm{O}, 8.24$.

\subsection{Experimental Design}

To evaluate the effects of nitrogen, phosphorus and vitamin on cell growth, lipid content and lipid productivity, an experimental central composite rotational design (CCRD) was carried out with two levels, minimum and maximum, coded as " -1 " and " +1 ", respectively, and four replicates of the center point (CP), coded as "0" (Table 1). As nitrogen, phosphorus and vitamins sources, $\mathrm{NaNO}_{3}$, a $1: 2 \mathrm{KH}_{2} \mathrm{PO}_{4}$ and $\mathrm{Na}_{2} \mathrm{HPO}_{4} \cdot 12 \mathrm{H}_{2} \mathrm{O}$ blend, and a 1:1:200 biotin, cyanocobalamin and thiamine blend, respectively, were used. The nutrient medium used was the same used by [14], changing the nitrogen and phosphorus concentrations, and adding vitamin according to each treatment, and keeping all others nutrients concentrations constants. Each phototrophic batch cultivation was carried out for ten days in $1 \mathrm{~L}$ Erlenmeyer flasks containing $800 \mathrm{~mL}$ of nutrients medium with initial $\mathrm{pH}$ 8.0, initial algal density around $2.0 \mathrm{E}+06$ cells $\mathrm{mL}^{-1}$, at a continuous light intensity of $400 \mu \mathrm{mol}$ photon $\mathrm{m}^{-2} \cdot \mathrm{s}^{-1}$ (illuminated by special day light lamp, OSRAM), light-dark cycles (L:D) of $12: 12$, under $23^{\circ} \mathrm{C}$, and with constant 
Table 1. Variables and levels used in the experimental central composite rotational design (CCRD) for nitrogen, phosphorus and vitamin concentration optimization in phototrophic cultivation of freshwater microalgae Scenedesmus sp.

\begin{tabular}{cccccc}
\hline Independent variable & Axial $-\alpha$ & Min -1 & CP 0 & Max +1 & Axial $\alpha$ \\
\hline Nitrogen $\left(\mathrm{mg} \cdot \mathrm{L}^{-1}\right.$ ) & 0.0 & 42.5 & 106.2 & 170.0 & 212.5 \\
Phosphorus $\left(\mathrm{mg} \cdot \mathrm{L}^{-1}\right.$ ) & 0.0 & 13.2 & 33.1 & 53.0 & 66.2 \\
Vitamin $\left(\mathrm{mg} \cdot \mathrm{L}^{-1}\right.$ ) & 0.0 & 0.13 & 0.32 & 0.50 & 0.63 \\
\hline
\end{tabular}

Min: minimum value, $\mathrm{CP}$ : center point, Max: maximum value.

aeration of $1.0 \mathrm{~L} \cdot \mathrm{min}^{-1}$. The light intensity was measured at the center of the flask by a Li-250A light meter (Li-COR Inc.) with a US-SQS-L pyranometer sensor (WALZ Inc.). The medium and flasks were sterilized in an autoclave for $20 \mathrm{~min}$ at $121^{\circ} \mathrm{C}$ in order to prevent any contamination during the early stages of growth. The air injected, and consequently $\mathrm{CO}_{2}$ contained in it, was esterilized after passing through an air filter $(0.2 \mu \mathrm{m}$ pore size, diameter $25 \mathrm{~mm}$, Chromafil).

\subsection{Microalgal Growth Property}

The algal density was determined every $24 \mathrm{~h}$ by measuring the cells number with a Fuchs-Rosenthal Counting Chamber under light microscope (Olympus SC30). The specific growth rate was calculated according to Equation (1):

$$
\mu=(\ln N T 2-\ln N T 1) /(T 2-T 1)
$$

where $T 1$ and $T 2$ is the beginning and end of the exponential growth phase, and $N T 1$ and $N T 2$ is the algal density at time $T 1$ and $T 2$, respectively. To determine ash free dry weight (AFDW), algal cultures were filtered through a glass microfiber filter paper $(0.45 \mu \mathrm{m}$ pore size, $47 \mathrm{~mm}$ in diameter, Whatman $)$, dried at $60^{\circ} \mathrm{C}$ in mechanical convection oven (Med Clave) to constant weight, and cooled at room temperature in desiccators. The filter paper was moved to $575^{\circ} \mathrm{C}$ furnace (EDG Equipamentos) for $60 \mathrm{~min}$. AFDW of the algal cells was calculated from the weight variation as indicated in Equation (2):

$$
\operatorname{AFDM}=\left(W-W^{\prime}\right) / V
$$

where $W$ is the weight after drying in $60^{\circ} \mathrm{C}$ oven, $W^{\prime}$ is the weight after drying in $575^{\circ} \mathrm{C}$ furnace, and $V$ is the volume. The biomass productivity $\left(P x, \mathrm{mg} \cdot \mathrm{L}^{-1} \cdot \mathrm{d}^{-1}\right)$ was calculated according to Equation (3):

$$
P X=\Delta X / \Delta T,
$$

where $\Delta X$ is the variation of biomass concentration $\left(\mathrm{mg} \cdot \mathrm{L}^{-1}\right.$ ) within a cultivation time of $\Delta T(\mathrm{~d})$.

\subsection{Determination of Lipid Content and Productivity}

After growth, biomass was harvested by centrifugation at $3500 \mathrm{rpm}$ for $15 \mathrm{~min}$, and then washed twice with deionized water to remove the salt in the medium. Lipid extraction was performed on wet biomass by [15] method. The lipid productivity $\left(P L, \mathrm{mg} \cdot \mathrm{L}^{-1} \cdot \mathrm{d}^{-1}\right)$ was calculated according to Equation (4):

$$
P L=(\Delta X \times L C) / \Delta T,
$$

where $\Delta X$ is the variation of biomass concentration $\left(\mathrm{mg} \cdot \mathrm{L}^{-1}\right), L C$ is the lipid content (\%) within a cultivation time of $\Delta T(\mathrm{~d})$.

\subsection{Fatty Acid Composition Analysis}

The lipid composition was determined as fatty acid methyl esters (FAMEs) through the saponification followed by methanolysis method [16]. Three hundred milligram samples were saponified with $1 \mathrm{~mL}$ of a saturated $\mathrm{KOH}-\mathrm{CH}_{3} \mathrm{OH}$ solution at $75^{\circ} \mathrm{C}$ for $10 \mathrm{~min}$, and then submitted to methanolysis with $5 \% \mathrm{HCl}$ in methanol at $75^{\circ} \mathrm{C}$ for another $10 \mathrm{~min}$. Thereafter, the phase containing the fatty acids was separated by adding $2 \mathrm{~mL}$ of distilled water and $2 \mathrm{~mL}$ of hexane, and then recovered from solvent phase through evaporation under vacuum. The 
composition of fatty acid methyl esters after methanolysis was analyzed using a gas chromatograph (GC-2014, Shimadzu, Kyoto, Japan) equipped with a flame ionization detector (FID). Samples were injected by using Split injector with flow rate of $20 \mathrm{~mL} \cdot \mathrm{min}^{-1}$ into a $30 \mathrm{~m}$-long Carbowax capillary column (Quadrex, USA) with polyethylene glycol stationary phase and an internal diameter of $0.32 \mathrm{~mm}$. The temperature of the injector and detector were both set at $250^{\circ} \mathrm{C}$. The oven temperature was set at $200^{\circ} \mathrm{C}$.

\subsection{Statistics Analysis}

Statistical analysis of the results was performed using Statistica software version 6.0 (StatSoft, Inc.). To maximize the three response variables, algal density and lipid content and productivity, simultaneously, an optimization using the global desirability function $(D)$ was performed, which consists in converting each response into a single desirability function ( $d i)$ that ranges from 0 to $1(0 \leq d i \leq 1)$. For a function with three independent variables, the global desirability function is expressed as indicated in Equation (5) [17]:

$$
D=(d 1 \times d 2 \times d 3)^{1 / 3}
$$

The predicted values were validated experimentally in phototrophic batch cultivation (four replicates), carried out in $1 \mathrm{~L}$ Erlenmeyer flasks, containing $800 \mathrm{~mL}$ of nutrients medium, at $400 \mu \mathrm{mol}$ photon $\mathrm{m}^{-2} \cdot \mathrm{s}^{-1}, \mathrm{~L}: \mathrm{D}$ 12:12, under $23^{\circ} \mathrm{C}$, and aeration of $1.0 \mathrm{~L} \cdot \mathrm{min}^{-1}$. Thus, the biomass produced in validation was submitted to determination of growth property and lipid content, and fatty acid composition analysis.

\section{Results and Discussion}

\subsection{Biomass and Lipid Production}

The cultivation kinetics of Scenedesmus sp. grown according to CCRD, are presented in Figure 1, showing the algal density as a function of time. After ten days of cultivation, the lowest algal density $\left(4.2 \mathrm{E}+06 \mathrm{cells} \mathrm{mL}^{-1}\right)$ was obtained in treatment 9, where culture medium did not contain nitrogen (N0) in its composition. The highest algal densities were reached with treatments $7\left(1.5 \mathrm{E}+07\right.$ cells $\left.\mathrm{mL}^{-1}\right)$ and $8\left(1.4 \mathrm{E}+07\right.$ cells $\left.\mathrm{mL}^{-1}\right)$, where culture medium contained nitrogen and phosphorus concentrations at maximum level $(+1)$. Based on algal densities achieved with treatments 10 and $12,1.2 \mathrm{E}+07$ and $1.1 \mathrm{E}+07$ cells $\mathrm{mL}^{-1}$, respectively, it was possible to notice that increasing nitrogen or alternatively phosphorus concentration from CP level to maximum level $(+1)$ gave similar results.

Figure 2 presents AFDW concentration, lipid content, and lipid productivity reached by each ten days batch carried out. Analyzing AFDW values, the highest were achieved with treatments $8\left(1.24 \mathrm{~g} \cdot \mathrm{L}^{-1}\right)$ and $7\left(1.21 \mathrm{~g} \cdot \mathrm{L}^{-1}\right)$,

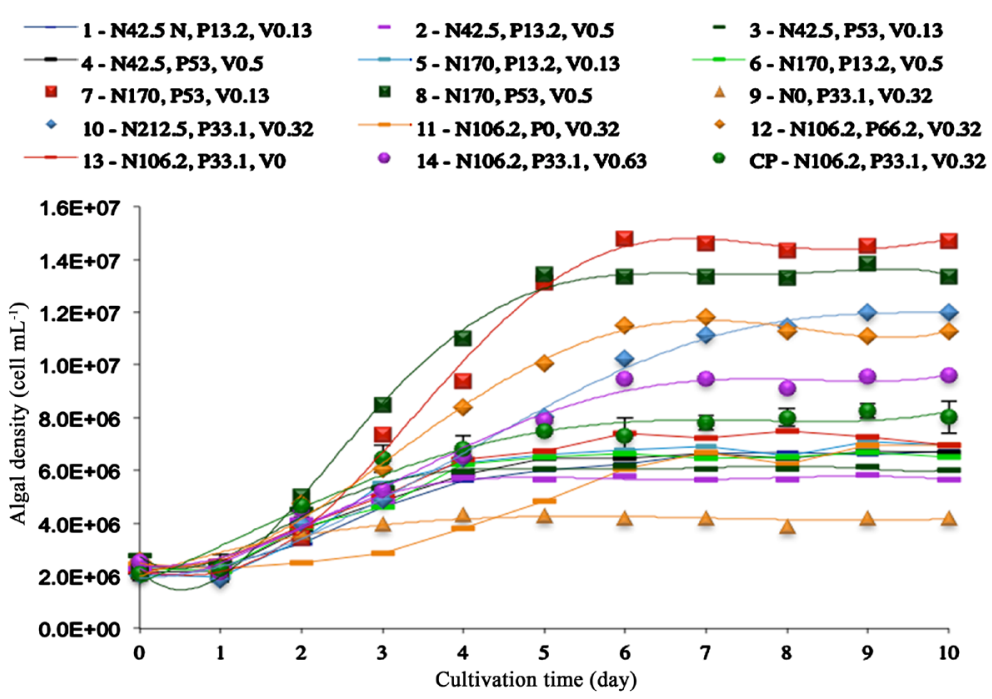

Figure 1. Effects of different concentrations of nitrogen $\left(\mathrm{N}, 0-170 \mathrm{mg} \cdot \mathrm{L}^{-1}\right)$, phosphorus $\left(\mathrm{P}, 0-66.2 \mathrm{mg} \cdot \mathrm{L}^{-1}\right)$ and vitamin $\left(\mathrm{V}, 0-0.63 \mathrm{mg} \cdot \mathrm{L}^{-1}\right)$ on the algal density during 10 days indoor cultivation of Scenedesmus sp. CP: center point. 


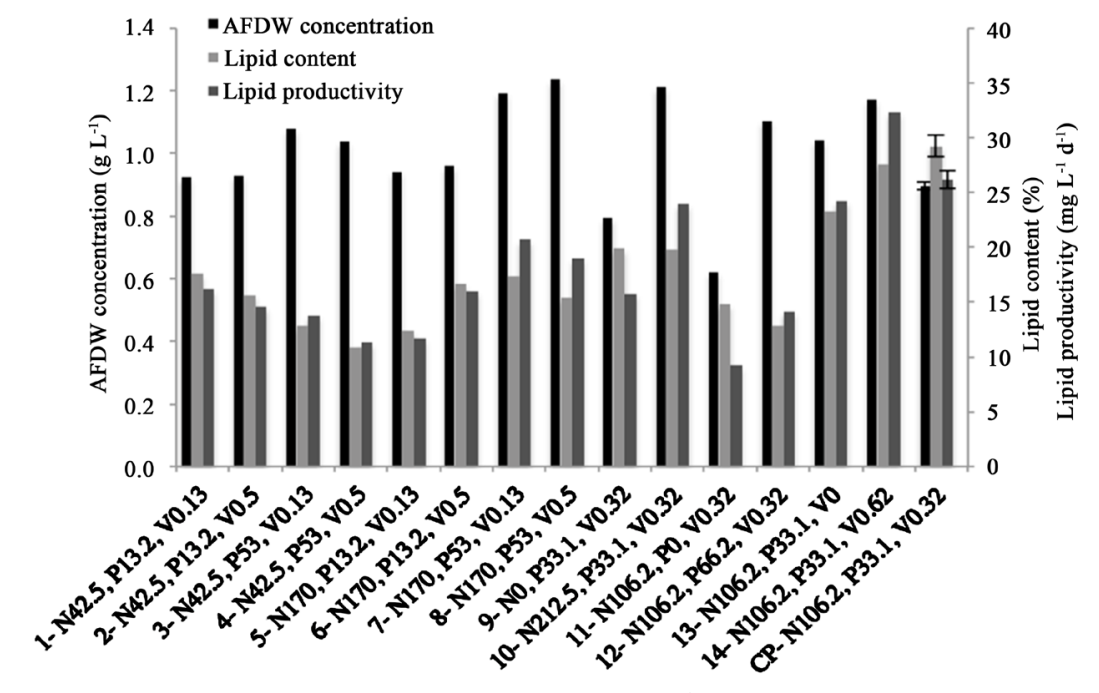

Nutrient concentration $\left(\mathrm{mg} \mathrm{L}^{-1}\right)$

Figure 2. AFDW concentration, lipid content and lipid productivity reached with each treatment $(1-14, \mathrm{CP})$ after 10 days indoor cultivation of Scenedesmus sp. N: nitrogen, $\mathrm{P}$ : phosphorus, $\mathrm{V}$ : vitamin, $\mathrm{CP}$ : center point.

where nitrogen and phosphorus concentrations were at its maximum level $(+1)$. On the other hand, with treatments 9 (N0) and $11(\mathrm{P} 0)$, the lowest AFDW, 0.80 and $0.62 \mathrm{~g} \cdot \mathrm{L}^{-1}$, respectively, were obtained. Therewith, the maximum biomass value obtained was 2.3 times higher than the reports of [1], which reported a biomass concentration of $0.54 \mathrm{~g} \cdot \mathrm{L}^{-1}$ when cultivating Scenedesmus obliquus with ambient $\mathrm{CO}_{2}$, and when cultivated at $35 \%$ of $\mathrm{CO}_{2}$ supply, it was reported a maximum biomass value of $1.39 \mathrm{~g} \cdot \mathrm{L}^{-1}$. The maximum biomass of $1.24 \mathrm{~g} \cdot \mathrm{L}^{-1}$ obtained with the Scenedesmus sp. SCIB-01 strain, without $\mathrm{CO}_{2}$ supply, was comparable to reports of [3] who obtained biomass concentration of $1.34 \mathrm{~g} \cdot \mathrm{L}^{-1}$ using $\mathrm{S}$. obliquus cultivated at $2.5 \% \mathrm{CO}_{2}$ feeding concentration. [8] reported S. obliquus cultivation at $30 \% \mathrm{CO}_{2}$ concentration, and obtained a biomass concentration of $1.03 \mathrm{~g} \cdot \mathrm{L}^{-1}$. [18] obtained a maximum biomass production of $0.41 \mathrm{~g} \cdot \mathrm{L}^{-1}$ using Desmodesmus sp. phototrophically cultivated, also lower than the values obtained with SCIB-01.

In this study, a maximum biomass productivity of $206.7 \mathrm{mg} \cdot \mathrm{L}^{-1} \cdot \mathrm{d}^{-1}$ was obtained, in which the cells achieved very high specific growth rate $(\mu), 0.62 \mathrm{~d}^{-1}$. The biomass productivity reached using SCIB-01 was greatly higher than that obtained using by Chlorella $\mathrm{sp} .\left(89 \mathrm{mg} \cdot \mathrm{L}^{-1} \cdot \mathrm{d}^{-1}\right)$, Scenedesmus $\mathrm{sp} .\left(94 \mathrm{mg} \cdot \mathrm{L}^{-1} \cdot \mathrm{d}^{-1}\right)$, Haematococcus sp. (51 mg. $\mathrm{L}^{-1} \cdot \mathrm{d}^{-1}$ ) and Nannochloropsis sp. (78 $\mathrm{mg} \cdot \mathrm{L}^{-1} \cdot \mathrm{d}^{-1}$ ) as was reported by [4]. [1] and [8] cultivated S. obliquus strain, and obtained lipid productivity values of $139.4 \mathrm{mg} \cdot \mathrm{L}^{-1} \cdot \mathrm{d}^{-1}$ and $81 \mathrm{mg} \cdot \mathrm{L}^{-1} \mathrm{~d}^{-1}$, respectively, still lower than that reached with SCIB-01. Moreover, the high specific growth rate $(\mu)$ of $0.62 \mathrm{~d}^{-1}$ reached with Scenedesmus sp. SCIB-01 was higher than that obtained from other Scenedesmus sp. (e.g., $0.22-0.57 \mathrm{~d}^{-1}$ according to [4] [19]) and other algal strain (e.g., $0.12-0.34 \mathrm{~d}^{-1}$ for Chlorella sp., $0.13-0.23 \mathrm{~d}^{-1}$ for Haematococcus sp., 0.13 - $0.31 \mathrm{~d}^{-1}$ for Nannochloropsis sp. according to [4]). Thus, even at much higher inlet concentration of $\mathrm{CO}_{2}$ as compared to literature reports, Scenedesmus sp. SCIB-01 showed superior or comparable biomass production.

The responses of Scenedesmus sp. cells studied here to lipid content showed that the highest one were achieved with treatments $14(27.6 \%)$ and CP $(29.3 \% \pm 1.1 \%)$ (Figure 2). When the medium did not contain nitrogen or its concentration was at level $+\alpha$, in treatments 9 and 10, respectively, the same lipid content of $19 \%$ was obtained. In the cases where the phosphorus was removed from the medium (treatment 11) or used at its axial level $(+\alpha)$ (treatment 12 ), lipid content decreased $49 \%$ and $56 \%$, respectively, compared with CP result. It was evidenced by these results that both absence and excess of nitrogen and phosphorus negatively affects the lipid content. Treatments 13 and 14 showed a lipid content increasing of $16 \%$ as a function of adding 0.62 $\mathrm{mg} \cdot \mathrm{L}^{-1}$ of vitamin, indicating its influence on lipid content.

The best conditions to achieve the highest lipid contents were also found to reach the maximum lipid productivity $\left(32.4 \mathrm{mg} \cdot \mathrm{L}^{-1} \cdot \mathrm{d}^{-1}\right.$ ). This can be noticed in treatments 13,14 , and 15 (Figure 2). Also, the nitrogen and phosphorus maintained at constant level and the increase of vitamin concentration provided a significant rise in lipid productivity. 
Generally, microalgae accumulate lipid under nutrient limitation when energy source (light) and carbon source $\left(\mathrm{CO}_{2}\right)$ are available and when the cellular mechanisms for the photosynthesis are active. In the present study at lower initial nutrient concentrations, Scenedesmus sp. accumulated lipid content six times higher than reported by [19], where the lipid content was $5 \%$ and $28.1 \%$ when $S$. quadricauda was cultivated at ambient $\mathrm{CO}_{2}$ and at $2 \%$ of $\mathrm{CO}_{2}$ supply, respectively. [2] reported lipid content of $16.41 \%$ and $15.31 \%$ for $C$. vulgaris and $N$. oculata, respectively. While [4] reported lipid content of $15.1 \%, 16.2 \%, 15.9 \%$, and $16.2 \%$ to Scenedesmus sp., Haematococcus sp., Chlorella sp., and Nannochloropsis sp., respectively, much lower than that obtained in this study (29.3\%), as can be noticed. Similar result was obtained by [20] using Chlorella sp., which accumulated 31.2\% of lipid. Previous study [10] described 20\% - 50\% lipid content of the dry cell weight was found to be quite common.

As was clearly observed, the algal density, AFDW and lipid content and productivity are differently influenced by the variation of nutrients concentrations. With the same nitrogen and phosphorus levels of original ASM-1 medium, the maximum algal density and AFDW concentration were obtained. However, using modified ASM-1, containing 38\% less nitrogen and phosphorus than the original medium, and with $0.31 \mathrm{mg} \cdot \mathrm{L}^{-1}$ of vitamin, was possible to reach lipid content and lipid productivity enhancements of $90 \%$ and $70 \%$, respectively.

\subsection{Optimization of Cell Growth, Lipid Content and Lipid Productivity}

A balance has to exist between the nutrient concentrations to improve both cell growth and lipid content, and consequently lipid productivity. Taking this into account, a statistical analysis of the experimental design results was performed toward determine the effects of nutrients on each response, and select conditions that maximize both dependent variables. From the statistical analysis, it was possible to plot the Pareto chart (Figure 3), which graphically and numerically presents the magnitude of the estimated effect of each independent variable, as well as the effect of their interactions. In this diagram, the effect is shown by bars, which only show statistical significance if they go beyond demarked vertical line for a significance of 95\% (p level 0.05) [17].

In Figure 3(A) it is possible to check that the generated linear effects $(\mathrm{L})$ by the nitrogen and phosphorus on algal density had statistical significance, followed by the generated significant effect by interaction between both variables. The statistical significance of this interaction showed that using nitrogen and phosphorus together achieving higher results were achieved than using them separately. Vitamin effect had not statistical significance

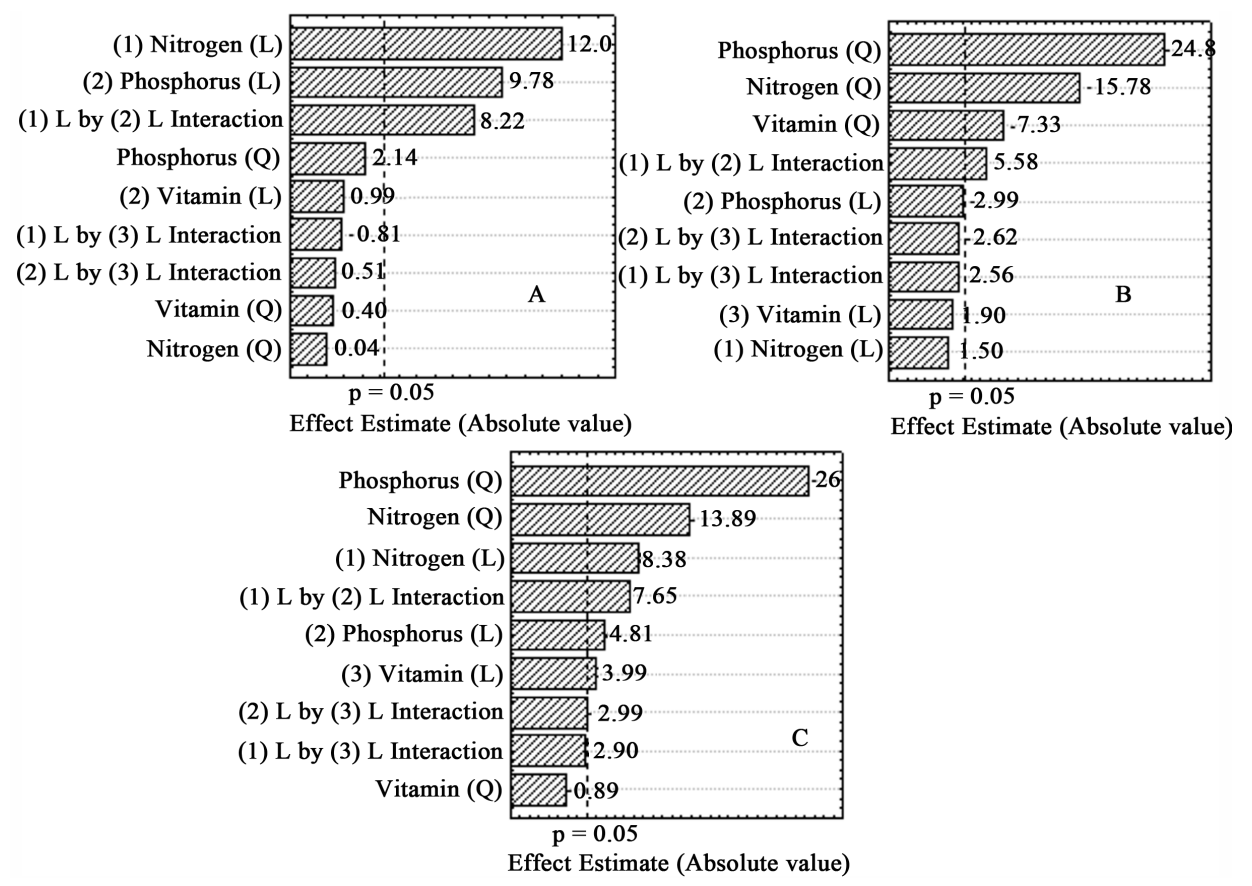

Figure 3. Pareto chart of standardized nutrients effects for algal density (A), lipid content (B), and lipid productivity (C) in the central composite rotational design (CCRD). 
on algal density, as well as its interaction with nitrogen and phosphorus. This means that nitrogen and phosphorus showed an effect, without vitamin interference. Figure 3(B) presents all effects on lipid content, and the generated effect of phosphorus had the highest statistical significance, followed by nitrogen and vitamin significant effects, and 1(L) by 2(L) interaction effect. This means the enhanced lipid accumulation was mainly due to the lack of phosphorus, rather than the absence of nitrogen or vitamin. Nitrogen, phosphorus and vitamin had significant effects on lipid productivity (Figure 3(C)) as it was for lipid content, being in agreement with the CCRD results. Additionally, the statistical analysis indicated an appropriated adjustment of the empirical model to the experimental results as confirmed by the high correlation coefficient obtained to algal density, lipid content and lipid productivity, $\mathrm{R}^{2}$ 0.95, 0.88, and 0.86, respectively. The statistical insignificance for the lack of fit (p level > 0.05) and the low pure error value corresponding to $15 \%$, or less, of the results magnitude, confirmed that the model was appropriate for predicting the results between the evaluated interval levels in the experimental design.

Figure 4 presents the response surface curves for the algal density, lipid content and lipid productivity. Algal density results shows that the conditions N212.5 and P66.2 were the best within the evaluated range, independently of vitamin concentrations. Although the response surface curves have not presented an absolute maximum, it could be reached by using higher nitrogen and phosphorus concentrations, as the center points are still lower than the factorial points, showing an increasing trend in the direction of the maximum point. Conversely, all response surfaces for lipid content and lipid productivity show a maximum point, as function nitrogen, phosphorus, and vitamin. Plainly, the lipid production by Scenedesmus sp. was maximized successfully through the nutrient optimization at N106.2, P33.1 and V0.32 levels.
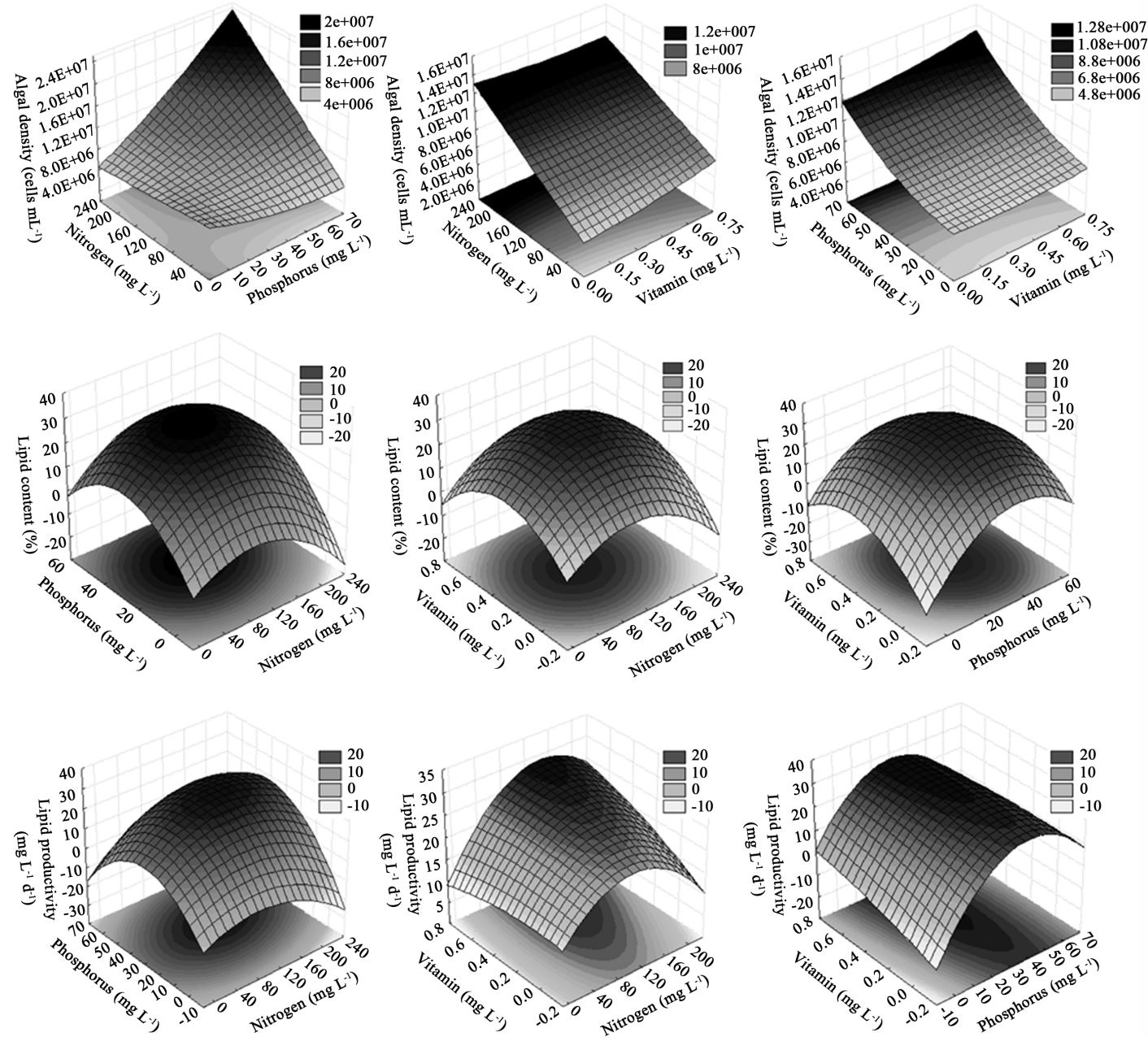

Figure 4. Response surface plots of CCDR for maximizing algal density (cell $\mathrm{mL}^{-1}$ ), lipid content (\%) and lipid productivity $\left(\mathrm{mg} \cdot \mathrm{L}^{-1} \cdot \mathrm{d}^{-1}\right)$. 


\subsection{Simultaneous Optimization Using the Global Desirability Function}

Nonetheless, the optimized conditions to lipid production was not ideal for algal density, and taking it as one of the aims of this study, a model to predict values that maximize both responses simultaneously, was accomplished through the desirability function. The global desirability value to reach the optimum was 0.76 , meaning that the optimization by this function fulfills $76 \%$ of the maximum obtainable for each response variable (Figure 5). The optimum concentration of nitrogen, phosphorus and vitamin was $159 \mathrm{mg} \cdot \mathrm{L}^{-1}, 49 \mathrm{mg} \cdot \mathrm{L}^{-1}$ and $0.32 \mathrm{mg} \cdot \mathrm{L}^{-1}$, respectively, to maximize biomass and lipid production simultaneously.

The predicted values determined by using the global desirability function and the experimental values obtained in validation of optimized conditions are presented in Table 2. It is observed that the experimental values are within the confidence limits $-95 \%$ and $+95 \%$, showing that the optimized values of nutrients were experimentally validated.

Thus, this present study was able to find optimum conditions to both lipid content and lipid productivity that usually are in contradiction with each other, as was reported by [9] [10]. This contradiction was also demonstrated throughout this study, where at lower initial concentrations of nutrient, Scenedesmus sp. accumulated high lipid content but produced low biomass. While at higher initial concentrations of nutrient, the microalga presented a high biomass production with low lipid accumulation. As high lipid productivity depends directly of both high biomass and lipid production, according to Equation (4), it is important to find favorable conditions for both responses, and the present study achieved this goal successfully using the Desirability function.

The lipid productivity obtained with optimized conditions $\left(25.2 \mathrm{mg} \cdot \mathrm{L}^{-1} \cdot \mathrm{d}^{-1}\right)$ is in agreement with [3], who obtained 21.2 - $45 \mathrm{mg} \cdot \mathrm{L}^{-1} \cdot \mathrm{d}^{-1}$ using different $S$. obliquus isolates. [19] reported lipid productivity around 18 $\mathrm{mg} \cdot \mathrm{L}^{-1} \cdot \mathrm{d}^{-1}$ using $S$. quadricauda grown under nitrogen starvation and ambient air, however when this alga was cultivated at $2.5 \% \mathrm{CO}_{2}$, a high lipid productivity $\left(140 \mathrm{mg} \cdot \mathrm{L}^{-1} \cdot \mathrm{d}^{-1}\right)$ was obtained. [2] showed values of 20.4 and $16.4 \mathrm{mg}$ of lipid $\mathrm{L}^{-1} \cdot \mathrm{d}^{-1}$ to $C$. vulgaris and $N$. oculata, respectively. [9] reported a lipid productivity of 20.3 $\mathrm{mg} \cdot \mathrm{L}^{-1} \cdot \mathrm{d}^{-1}$ using also a Scenedesmus sp. strain, but its lipid accumulation rate was lower than that achieved by SCIB-01.

This study is in accord to many earlier reports that suggest that under nutrient-deprived conditions microalgae can accumulate lipid, making use of the available carbondioxide and solar energy [3] [13] [18]. The response towards the different stress conditions is highly dependent on the species investigated. When the biomass grown under normal conditions was transferred to nutrients-depleted medium (nitrogen, phosphorus and vitamin),
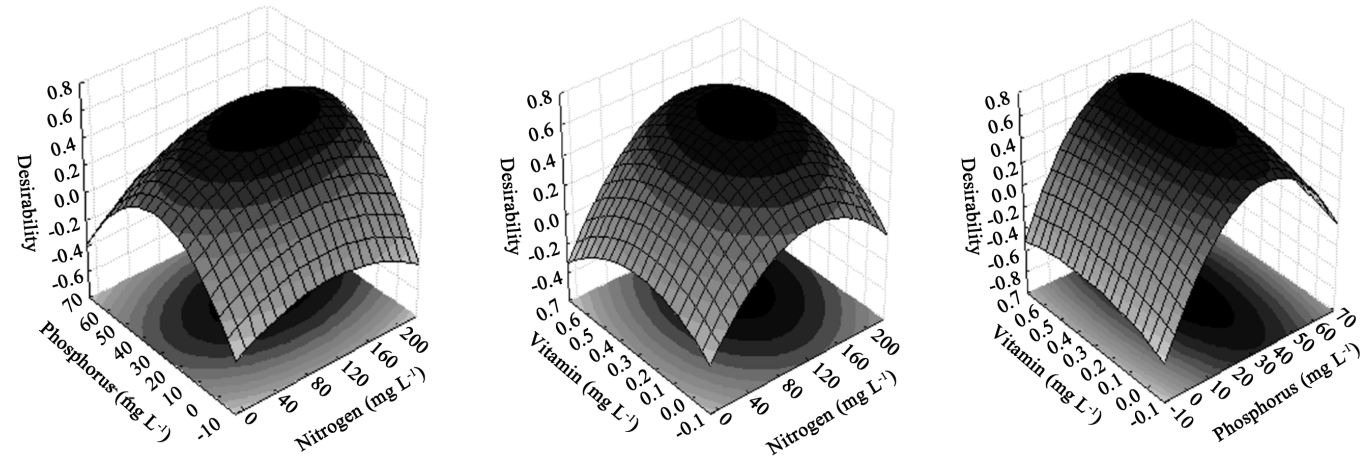

Figure 5. Response surface plots of CCRD for desirability function to maximize the cell growth and lipid accumulation simultaneously.

Table 2. Validation of the nutrients concentration optimization.

\begin{tabular}{|c|c|c|c|c|c|c|c|}
\hline \multirow{2}{*}{ Responses } & \multicolumn{2}{|c|}{ Limits } & \multirow{2}{*}{$\begin{array}{c}\mathrm{N} \\
\left(\mathrm{mg} \cdot \mathrm{L}^{-1}\right)\end{array}$} & \multirow{2}{*}{$\begin{array}{c}\mathrm{P} \\
\left(\mathrm{mg} \cdot \mathrm{L}^{-1}\right)\end{array}$} & \multirow{2}{*}{$\begin{array}{c}\mathrm{V} \\
\left(\mathrm{mg} \cdot \mathrm{L}^{-1}\right)\end{array}$} & \multirow{2}{*}{ Predicted value } & \multirow{2}{*}{ Experimental result } \\
\hline & $-0.95 \%$ & $+0.95 \%$ & & & & & \\
\hline Algal density (cell mL ${ }^{-1}$ ) & $1.27 \mathrm{E}+07$ & $1.47 \mathrm{E}+07$ & \multirow{2}{*}{159} & \multirow{2}{*}{49} & \multirow{2}{*}{0.32} & $1.37 \mathrm{E}+07$ & $1.30 \pm 0.08 \mathrm{E}+07$ \\
\hline Lipid content (\%) & 18.5 & 23.2 & & & & 19.7 & $20.3 \pm 2.6$ \\
\hline
\end{tabular}

N: nitrogen, P: phosphorus, V: vitamin. 
Scenedesmus sp. was able to respond with different levels of lipid accumulation and showed a profound increase in lipid content, with a minor loss in biomass, which was very similar to the results reported by [20]. This could be explained from the perspective that under nitrogen-deprived condition the cell would release nitrogen from the photosynthetic pigments and utilize it for the metabolic processes. This would bring down the rate of photosynthesis leading to a cellular metabolic flux, and therefore, NADH would accumulate. This would inhibit the enzyme citrate synthase and stop acetyl CoA from entering the TCA cycle. The increase in the level of acetyl CoA would lead to activation of acetyl CoA carboxylase, which in turn would convert acetyl CoA in to malonyl CoA. As a result, lipid synthesis would increase, resulting in increased lipid accumulation [21].

From economical perspective, the nutrient deprivation can be considered a suitably strategy since it is only involves minimal and cost-effective nutrients and thereby has a great significance on the overall economics. For instance, wastewater containing the nutrient concentrations indicated as the best by this present study could be used with this purpose. Since it is well known that Scenedesmus species have the most desirable features for wastewater treatment and lipid synthesis toward biodiesel production [7]-[9].

\subsection{Analysis of the Microalgae Lipids}

The important biodiesel properties such as cetane number, iodine number, heat of combustion, NOx emission, oxidative stability, lubricity, viscosity and cold flow are solely dependent on the FAME profile. Usually, the presence of unsaturated fatty acids leads to lowering of the cetane number of a biodiesel and increase in the NOx emission. The unsaturated fatty acids are prone to oxidation, which would also affect the lubricity of a biodiesel [20]. Hence, it is essential that the biodiesel must have high levels of saturated and monounsaturated fatty acids with low levels of polyunsaturated fatty acids.

In the present study, the analysis of Scenedesmus sp. fatty acids profile revealed the presence of palmitic (C16:0), oleic (C18:1), linoleic (C18:2) and linolenic (C18:3) acids as the major fatty acids (Table 3). Thus, the fatty acid profile was dominated by monounsaturated (MUFA) and saturated (SFA) fatty acids, comprising 82.95\% of the entire pool, while polyunsaturated acids (PUFA) accounted for less than $18 \%$. Many reports have evaluated the fatty acids composition of microalgae. [13] reported that the highest C16 and C18 series content (as \% of total FAME) of $S$. rubescens at post-logarithmic growth phase was $62 \%$, lower than that obtained in this study (83.4\%), with similar predominance of 16:0, 18:0, 18:1 and 18:2 fatty acids. [20] reported that the highest C16 and C18 series content in Chlorella sp. was $64.1 \%$ but the C16 series content was only $1.1 \%$ of total FAME, and the MUFA and SFA comprised less than $76 \%$ under nitrogen deprivation. Main fatty acid composition of S. obliquus cultivated with $2.5 \% \mathrm{CO}_{2}$ by [3] were $\mathrm{C} 16$ and $\mathrm{C} 18$ groups, which accounted for $76 \%-84 \%$ of the total fatty acids. The report of [4] showed very high C16 and C18 series content to Chlorella sp., Scenedesmus sp., Haematococcus sp., and Nannochloropsis sp., 97.5\%, 95\%, 89.5\% and 83\%, respectively.

Table 3. FAME composition of extracted Scenedesmus sp. oil under nutrients optimized conditions.

\begin{tabular}{cccc}
\hline Fatty acid methyl esters (FAME) & Nature & \% Composition \\
\hline Lauric & $12: 0$ & SFA & 0.57 \\
Myristic & $14: 0$ & SFA & 5.33 \\
Palmitic & $16: 0$ & SFA & 38.12 \\
Palmitoleic & $16: 1$ & MUFA & 3.92 \\
Stearic & $18: 0$ & SFA & 1.50 \\
Oleic & $18: 1$ & MUFA & 26.45 \\
Linoleic & $18: 2$ & PUFA & 7.26 \\
Linolenic & $18: 3$ & PUFA & 6.10 \\
Arachidic & SFA & 4.04 \\
Eicosapentaenoic & PUFA & 0.69 \\
Behenic & $20: 0$ & SFA & 1.41 \\
Lignoceric & $22: 0$ & SFA & 1.61 \\
\hline
\end{tabular}


It is already clear that the FAME profile have to be in agreement with the desirable biodiesel properties. However, there are others characteristics to be considered, as the dewatering process of microalgae since it is an important economical point to have a cost-effective biodiesel. Therewith, it is desirable to extract lipid directly from wet microalgae, how was performed in this study, because the dewatering process to obtain dried microalgae is costly, although the studies on wet lipid extraction have been very limited [11] [12]. Thus, Scenedesmus sp. SCIB-01 cultivated under the optimum conditions found by this study seems to be an excellent candidate as biodiesel feedstock.

\section{Conclusion}

The experimental design strategy combined with the use of the desirability function for the optimization of nitrogen, phosphorus and vitamin showed to be a successful tool for maximizing cell and oil production simultaneously. The high biomass and lipid production under nutrient deprivation and ambient air supply could decrease the cost of the biodiesel production. Hence, the high proportion of C16 and C18 in the lipids showed Scenedesmus sp. to be a potential microalgae species for biodiesel production.

\section{Acknowledgements}

The authors are deeply grateful to the Brazilian Council for Research (CAPES) and the Brazilian Oil Company (PETROBRAS) for grants and other financial supports.

\section{References}

[1] Basu, S., Roy, A.S., Mohanty, K. and Ghoshal, A.K. (2014) $\mathrm{CO}_{2}$ Biofixation and Carbonic Anhydrase Activity in Scenedesmus obliquus SA1 Cultivated in Large Scale Open System. Bioresource Technology, 164, 323-330. http://dx.doi.org/10.1016/j.biortech.2014.05.017

[2] Converti, A., Casazza, A.A., Ortiz, E.Y., Perego, P. and Del Borghi, M. (2009) Effect of Temperature and Nitrogen Concentration on the Growth and Lipid Content of Nannochloropsis oculata and Chlorella vulgaris for Biodiesel Production. Chemical Engineering and Processing, 48, 1146-1151. http://dx.doi.org/10.1016/j.cep.2009.03.006

[3] Ho, S.H., Chen, C.Y. and Chang, J.S. (2012) Effect of Light Intensity and Nitrogen Starvation on $\mathrm{CO}_{2}$ Fixation and Lipid/Carbohydrate Production of an Indigenous Microalga Scenedesmus obliquus CNW-N. Bioresource Technology, 113, 244-252. http://dx.doi.org/10.1016/j.biortech.2011.11.133

[4] Andruleviciute, V., Makareviciene, V., Skorupskaite, V. and Gumbyte, M. (2014) Biomass and Oil Content of Chlorella sp., Haematococcus sp., Nannochlopsis sp. and Scenedesmus sp. under Mixotrophic Growth Conditions in the Presence of Technical Glycerol. Journal Applied Phycology, 26, 83-90. http://dx.doi.org/10.1007/s10811-013-0048-X

[5] Siaut, M., Cuine, S., Cagnon, C., Fessler, B., Nguyen, M., Carrier, P., Beyly, A., Beisson, F., Triantaphylides, C., Li-Beisson, Y.H. and Peltier, G. (2011) Oil Accumulation in the Model Green Alga Chlamydomonas reinhardtii: Characterization, Variability between Common Laboratory Strains and Relationship with Starch Reserves. BMC Biotechnology, 11, 7. http://dx.doi.org/10.1186/1472-6750-11-7

[6] Chisti, Y. (2007) Biodiesel from Microalgal. Biotechnology Advances, 25, 294-306. http://dx.doi.org/10.1016/j.biotechadv.2007.02.001

[7] Blersch, D.M., Kangas, P.C. and Mulbry, W.W. (2013) Turbulance and Nutrient Interactions That Control Benthic Algal Production in an Engineered Cultivation Raceway. Algal Research, 2, 107-112. http://dx.doi.org/10.1016/j.algal.2013.01.001

[8] Tang, D., Han, W., Li, P., Miao, X. and Zhong, J. (2011) $\mathrm{CO}_{2}$ Fixation and Fatty Acid Composition of Scenedesmus obliquus and Chorella pyrenoidosa in Response to Different $\mathrm{CO}_{2}$ Levels. Bioresource Technology, 102, 3071-3076. http://dx.doi.org/10.1016/j.biortech.2010.10.047

[9] Xin, L., Ying, H.H., Ke, G. and Xue, S.Y. (2010) Effects of Different Nitrogen and Phosphorus Concentrations on the Growth, Nutrient Uptake, and Lipid Accumulation of a Freshwater Microalga Scenedesmus sp. Bioresource Technology, 101, 5494-5500. http://dx.doi.org/10.1016/j.biortech.2010.02.016

[10] Liu, J., Huang, J.C., Fan, K.W., Jiang, Y., Zhong, Y.J., Sun, Z. and Chen, F. (2010) Production Potential of Chlorella zofingienesis as a Feedstock for Biodiesel. Bioresource Technology, 101, 8658-8663. http://dx.doi.org/10.1016/j.biortech.2010.05.082

[11] Mata, T.M., Martins, A.A. and Caetano, N.S. (2010) Microalgae for Biodiesel Production and Other Applications: A Review. Renewable and Sustainable Energy Reviews, 14, 217-232. http://dx.doi.org/10.1016/j.rser.2009.07.020 
[12] Rawat, I., Ranjith Kumar, R., Mutanda, T. and Bux, F. (2013) Biodiesel from Microalgae: A Critical Evaluation from Laboratory to Large Scale Production. Applied Energy, 103, 444-467. http://dx.doi.org/10.1016/j.apenergy.2012.10.004

[13] Yeh, K.L. and Chang, J.S. (2012) Effects of Cultivation Conditions and Media Composition on Cell Growth and Lipid Productivity of Indigenous Microalga Chlorella vulgaris ESP-31. Bioresource Technology, 105, 120-127. http://dx.doi.org/10.1016/j.biortech.2011.11.103

[14] Gorham, P.R., Mclachilan, J.R., Hammer, V.T. and Kim, W.K. (1964) Isolation and Culture of Toxic Strains of Anabaena Flos-Aquae (Lyngb.) de Bréb. Verhandlungen der Internationalen Vereinigung für Theoretischeund Angewandte Limnologie, 15, 796-804.

[15] Bligh, E.G. and Dyer, W.J. (1959) A Rapid Method of Total Lipid Extraction and Purification. Canadian Journal of Biochemistry and Physiology, 37, 911-917. http://dx.doi.org/10.1139/059-099

[16] Lee, J.Y., Yoo, C., Jun, S.Y., Ahn, C.Y. and Oh, H.M. (2010) Comparison of Several Methods for Effective Lipid Extraction from Microalgae. Bioresource Technology, 101, S75-S77. http://dx.doi.org/10.1016/j.biortech.2009.03.058

[17] Montgomery, D. and Calado, V. (2003) Experimental Design Using the Statistic. Editorial E-Papers Serviços Editoriais, Rio de Janeiro.

[18] Ji, F., Liu, Y., Hao, R., Li, G., Zhou, Y.G. and Dong, R.J. (2014) Biomass Production and Nutrients Removal by a New Microalgae Strain Desmodesmus sp. in Anaerobic Digestion Wastewater. Bioresource Technology, 161, $200-207$. http://dx.doi.org/10.1016/j.biortech.2014.03.034

[19] Zhao, G., Yu, J., Jiang, F., Zhang, X. and Tan, T.W. (2012) The Effect of Different Trophic Modes on Lipid Accumulation of Scenedesmus quadricauda. Bioresource Technology, 114, 466-471. http://dx.doi.org/10.1016/j.biortech.2012.02.129

[20] Praveenkumar, R., Shameera, K., Mahalakshmi, G., Arbarsha, M.A. and Thajuddin, N. (2012) Influence of Nutrient Deprivations on Lipid Accumulation in a Dominant Indigenous Microalga Chlorella sp., BUM11008: Evaluation for Biodiesel Production. Biomass and Bioenergy, 37, 60-66. http://dx.doi.org/10.1016/j.biombioe.2011.12.035

[21] Mandal, S. and Mallick, N. (2009) Microalga Scenedesmus obliquus as a Potential Source for Biodiesel Production. Applied Microbiology and Biotechnology, 84, 281-291. http://dx.doi.org/10.1007/s00253-009-1935-6 
Scientific Research Publishing (SCIRP) is one of the largest Open Access journal publishers. It is currently publishing more than 200 open access, online, peer-reviewed journals covering a wide range of academic disciplines. SCIRP serves the worldwide academic communities and contributes to the progress and application of science with its publication.

Other selected journals from SCIRP are listed as below. Submit your manuscript to us via either submit@scirp.org or Online Submission Portal.
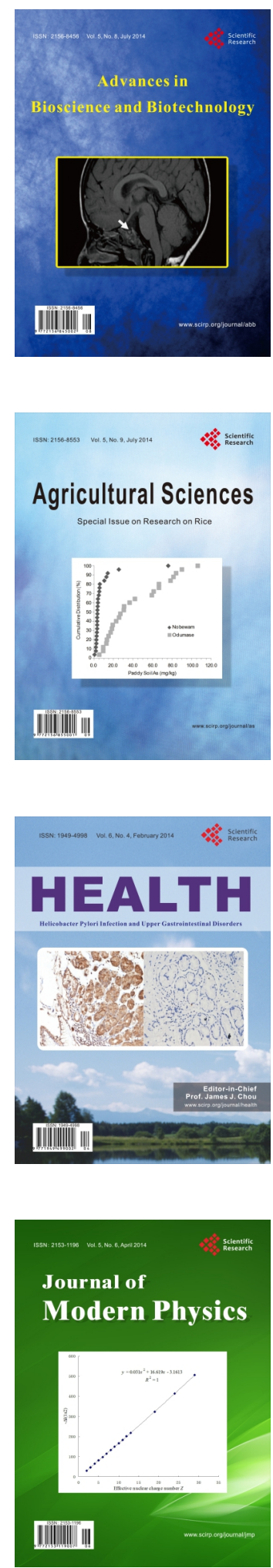
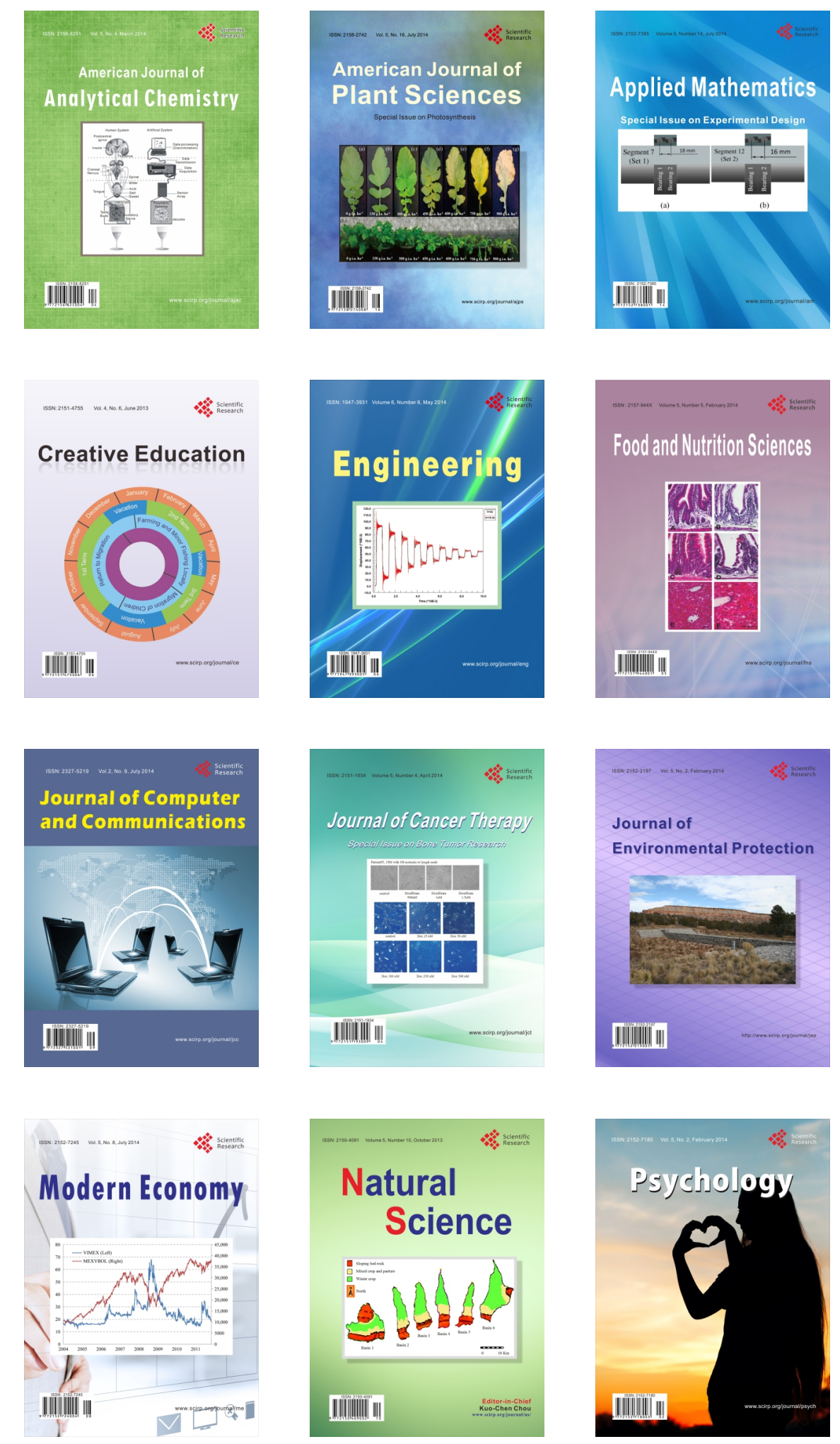